\title{
Osborn, Salzman, Barkovich et al.: Diagnostic imaging: brain. 2nd edition
}

\author{
Amirsys, pp 1266, (ISBN-10: 1931884722 ISBN-13: 978-1931884723) £233
}

\author{
Kirsten Forbes
}

Received: 7 September 2011 / Accepted: 8 September 2011 /Published online: 17 September 2011

(C) Springer-Verlag 2011

The 2nd edition of this textbook is already frequently found on the radiology reporting room, reinforcing its role as an important reference guide to neuroimaging.

This new edition offers updated information including new diagnoses and images, allowing the readers to maintain their edge in this rapidly changing field; purchase of the updated version is therefore recommended. The book reuses the now proven successful format of bulleted points including key facts, imaging findings, and differential diagnosis, providing an easy-to-access reference work. By dividing the book into two sections, it allows the reader to review diagnosis either by

K. Forbes $(\bowtie)$

Department of Neuroradiology, Institute of Neurological Sciences,

Southern General Hospital,

1345 Govan Road,

Glasgow G51 4TF, UK

e-mail: Kirsten.Forbes@ggc.scot.nhs.uk pathology or anatomic base, as is done in clinical practice. It offers an excellent overview of imaging findings, which is particularly useful to dip into in the reporting room or when preparing for examinations; however, there clearly still remains a market for the more traditional textbook, which often offers a more guided walk through a topic and often more detailed information.

The book contains contributions from 28 different neuroradiologists practicing in the USA, each offering expertise in their particular subspecialist area of neuroradiology. It covers the full range of neuroradiology topics, offering excellent graphic examples. The included online version is easy to use, with maximal text and excellent quality images, and is likely to be widely used at a PACS workstation. The easy-to-access information within Diagnostic Imaging: Brain makes it likely to continue as a leading textbook, not only for neuroradiologists and general radiologists but likely also neurologists, and neurosurgeons. 